\title{
Morphological Study by TE M on Thin Films of Nylon-6, Nylon-6,6, and Their Blends As-cast from Formic Acid Solution
}

\author{
Masaki Tsujı, ${ }^{\dagger}$ Tadahiro TogAMi, Elinor L. BEDIA, ${ }^{*}$ \\ Masayoshi OHARA, and Shinzo KOHJIYA \\ Laboratory of Polymer Condensed States, Division of States and Structures III, Institute for Chemical \\ Research, Kyoto University, Uji, Kyoto-Fu 611-0011, Japan \\ ${ }^{*}$ Materials Science Division, Industrial Technology Development Institute, Bicutan, \\ Taguig, Metro-Manila, Philippines
}

(Received December 5, 2001; Accepted March 18, 2002)

KEY WORDS Nylon-6 / Nylon-6,6 / Polymer Blend / Solution-Cast Thin Film / Transmission
Electron Microscopy / Electron Diffraction / Morphology /

Nylon-6 (polycaprolactam) (N6) and nylon-6,6 (poly(hexamethylene adipamide)) (N66) are very important commercial polymers in the nylon family. ${ }^{1} \mathrm{By}$ blending these two polymers, a remarkable improvement on their inherent mechanical properties can be expected. Extensive efforts have been, therefore, made for mechanical, thermodynamic and/or structural studies of the blends. ${ }^{2-11} \mathrm{~N} 6$ and N66 are miscible in their molten state, ${ }^{1}$ and are also expected to be miscible in their solution state. ${ }^{7}$ Some morphological studies by transmission electron microscopy (TEM) of as-solution-cast crystalline thin films of each pure component have been reported so far (e.g., refs 6, 12, and 13 for N6, and refs 6,14 , and 15 for N66; mostly, cast from solutions in formic acid), but there have been few reports on morphology of their blend films as-cast from solution. ${ }^{6}$ In particular, although selected-area electron diffraction (SAED) patterns obtained from the same specimenarea tilted at a series of angles are very important to identify the crystal modifications and/or crystallite orientation in a given specimen film, such SAED experiments by specimen-tilting have been done in a few reports only on N66 ${ }^{14,15}$ and in no report on their blends, to our knowledge. In this communication, we report some results on morphology of the thin films of N6, N66 and their blends, all of which were prepared by casting the respective solutions in formic acid onto water surface, and also on a set of SAED patterns recorded from the un-tilted and tilted specimen-area for each of the thin films.

\section{EXPERIMENTAL}

\section{Materials and Preparation of Thin Films}

N6 $\left(M_{\mathrm{w}}=16000\right)$ and N66 $\left(M_{\mathrm{w}}=22000\right)$ are respectively the products of Unitika Ltd. (A1030BRL) and BASF Co. (R8270), both of which were kindly supplied by Research and Development Center, Unitika Ltd. and were the same materials investigated by Hirami and his co-workers ${ }^{7-10}$ and by Bedia et al. ${ }^{11}$

The procedure to make solutions in formic acid is similar to that reported previously: ${ }^{11}$ Solutions $(0.2$ wt $\%$ ) of N6 and N66 were separately prepared at room temperature (RT) by dissolving each nylon in formic acid (this concentration, $0.2 \mathrm{wt} \%$, was determined by trial and error to be just appropriate for our purpose). In order to make blends of desired $\mathrm{wt} \%$ compositions $(\mathrm{N} 6 / \mathrm{N} 66=30 / 70,50 / 50$ and 70/30), the corresponding volume ratios of N6 and N66 solutions were mixed together at RT. Thin polymer films were prepared from each of the resulting solutions by casting onto the surface of water thermostated at 55,65 , or $75^{\circ} \mathrm{C}$. Of course, these three temperatures are much lower than the melting temperature of N6 crystal and also that of N66 one. ${ }^{11}$

Rybnikár and Geil ${ }^{6}$ prepared a specimen film for TEM by evaporating a drop of solution directly on a carbon-coated TEM grid or on a glass slide. Direct evaporation of a solution in formic acid on the TEM grid, however, may leave a residue of formic acid in the resulting film, and such a residue is harmful to a TEM column. In order to minimize this danger and for in- 

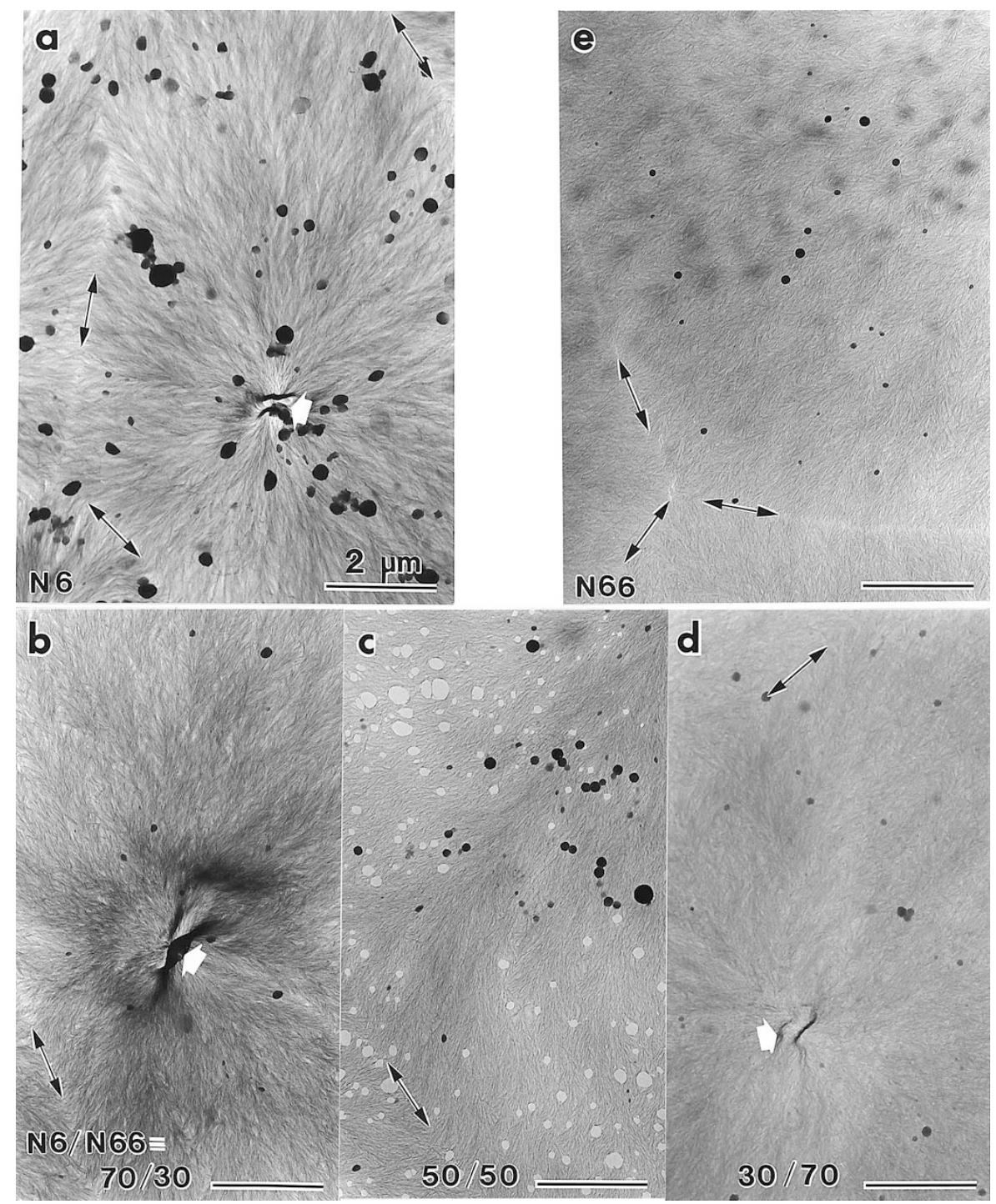

Figure 1. Thin films of N6, N66 and their blends, which were as-cast from respective $0.2 \mathrm{wt} \%$ solutions in formic acid onto the surface of water thermostated at $65^{\circ} \mathrm{C}$ and were not metal-shadowed or stained. In each TEM photograph, the scale bar expresses $2 \mu \mathrm{m}$ and a doubleheaded arrow designates the boundary between impinged spherulites. The white thick arrow indicates the center of a spherulite in each of (a), (b), and (d). (a) N6, namely N6/N66 = 100/0. (b) N6/N66=70/30. (c) N6/N66=50/50. (d) N6/N66=30/70. (e) N66, namely N6/N66 $=0 / 100$.

stantaneous judgement of the quality of specimen film, the solution-casting method on the water surface is employed in this study.

\section{Specimen Preparation for Transmission Electron Mi- croscopy (TEM)}

A polymer thin film floating on water surface was mounted onto a copper grid for TEM and dried under ambient conditions. The specimens thus prepared were examined by TEM (with a JEOL JEM-100U operated at $80 \mathrm{kV}$ and a JEOL JEM-200CS operated at $200 \mathrm{kV}$ ). Ordinary bright-field morphological images were obtained in the amplitude (namely, mass-thickness and/or diffraction) contrast mode mostly with the JEM-100U. SAED patterns were obtained with the JEM-200CS equipped with a conventional specimen-tilting holder
(JEOL EM-SQH): Each of the SAED patterns was taken from a specimen area about $8 \mu \mathrm{m}$ in diameter and this area contained, roughly speaking, a twodimensional spherulite or a central part of a larger one (see Figure 1). In order to calibrate the diffraction camera length, the specimens for SAED experiment were coated with vapor-deposited gold $(\mathrm{Au})$. All the images and SAED patterns were recorded on photographic films (Mitsubishi MEM).

\section{RESULTS AND DISCUSSION}

Optimal Temperature of Water to Obtain Thin Films for TEM, and Their Morphologies

Figure 1 shows morphologies of the resulting thin films that were all made at the same temperature $\left(65^{\circ} \mathrm{C}\right)$ 
of water. In all the films of N6, N66 and their blends, long fibrillar entities are clearly observed. (Dark particle-like entities observed in all the films are supposed to be dust particles and/or non-crystalline precipitates of polymer.) As indicated below, SAED patterns revealed that all the films thus prepared are crystalline. All the films have spherulitic textures consisting of closely impinged spherulites whose diametrical size is $c a .10-c a .20 \mu \mathrm{m}$, and typical examples of twodimensional spherulites are well recognized in Figures $1 \mathrm{a}$ and $1 \mathrm{~b}$. The center of such a spherulite is surely observed in each of Figures $1 \mathrm{a}, 1 \mathrm{~b}$, and $1 \mathrm{~d}$, as indicated with a thick white arrow. In Figures 1c and 1e, however, the center of a rather large spherulite appears to be located outside the upper right corner of each photograph. The boundaries between impinged spherulites are clearly recognized, for example, in Figures 1a and $1 \mathrm{e}$ where such a boundary is designated with a doubleheaded arrow.

The best temperatures to prepare desired thin films of N6 $(\mathrm{N} 6 / \mathrm{N} 66=100 / 0)$ and N66 (N6/N66 = 0/100) were $75^{\circ} \mathrm{C}$ and $55^{\circ} \mathrm{C}$, respectively. The second best one for both $\mathrm{N} 6$ and $\mathrm{N} 66$ was $65^{\circ} \mathrm{C}$. The best films of a blend of N6/N66 $=30 / 70$ could be made at $65^{\circ} \mathrm{C}$. As for both N6/N66 $=70 / 30$ and 50/50, fairly good films could be prepared at all the three temperatures. In Figure 1c, however, a number of small holes are visible probably because this part of the specimen film of N6/N66 $=50 / 50$ was accidentally very thin.

As mentioned above, $65^{\circ} \mathrm{C}$ was the second best temperature for preparing N6 films and N66 ones, but it was concluded that $65^{\circ} \mathrm{C}$ was the optimal temperature for $0.2 \mathrm{wt} \%$ solutions of all the blend compositions utilized here. We supposed that the temperature of water should be fixed for comparing the SAED patterns obtained from specimen films of different compositions, and the patterns obtained from the films prepared at $65^{\circ} \mathrm{C}$ will be shown in Figure 2. Accordingly, the corresponding morphologies of the films made at $65^{\circ} \mathrm{C}$ have been demonstrated in Figure 1.

\section{SAED Patterns from the Resulting Films}

Firstly a SAED pattern was recorded at $0^{\circ}$, namely without specimen tilting (see Figures 2a-2e), after locating the center of a spherulite approximately on the optical axis of the TEM column. Then the specimen area used for taking the "untilted" SAED pattern was tilted in the TEM column by $50^{\circ}$ around the vertical axis (i.e., the axis parallel to the meridian, as indicated in Figure 2a), and another SAED pattern was recorded (Figures $2 \mathrm{a}^{\prime}-2 \mathrm{e}^{\prime}$ ). The lattice spacing for each reflection observed in all SAED patterns was estimated, by calibrating the diffraction camera length with the aid of the 111 reflection-ring from vapor-deposited $\mathrm{Au}$ (see Figure 2a). Major difference in reflection intensity of nylon crystals from pattern to pattern in Figure 2 is attributable to the difference in film thickness.

(1) N6 films $(N 6 / N 66=100 / 0)$. Figure $2 \mathrm{a}$ is a SAED pattern obtained at $0^{\circ}$ (untilted) in which only one reflection-ring is observed. This reflection-ring is very sharp and has fairly uniform intensity distribution along the Debye-Scherrer circle. The lattice spacing of this reflection-ring was estimated at $0.411 \mathrm{~nm}$. A weak, diffuse ring-like halo is observed just inside the reflection-ring. When the specimen-area used for Figure $2 \mathrm{a}$ was tilted around the vertical axis by $50^{\circ}$, the equatorial part of this sharp reflection-ring disappeared and the meridional part still remained, as shown in Figure $2 a^{\prime}$. The four off-meridional parts on the same Debye-Scherrer circle increased in intensity, showing a four-point-like reflection. No other reflections, however, are observed in Figure $2 a^{\prime}$. The lattice spacing of the reflection observed in Figure $2 \mathrm{a}^{\prime}$ was estimated at $0.410 \mathrm{~nm}$. On the basis of the X-Ray diffraction experiments, Ohta et al. ${ }^{16}$ reported that N6 films cast from solution in aqueous formic acid have the $\gamma$-form (monoclinic). In this work, the following lattice constants of $\mathrm{N} 6 \gamma$-form reported by Arimoto et al. ${ }^{17}$ are cited: monoclinic $\left(P 2_{1} / a\right) ; a=0.933 \mathrm{~nm}, b$ (chain axis) $=1.688 \mathrm{~nm}, c=0.478 \mathrm{~nm}, \beta=121^{\circ}$. The reflection ring (measured lattice spacing $=0.411 \mathrm{~nm}$ ) in Figure $2 \mathrm{a}$ and the reflection $(0.410 \mathrm{~nm})$ in Figure $2 \mathrm{a}^{\prime}$ cannot be expected from the N6 $\alpha$-form (monoclinic $\left(P 2_{1}\right)$; $a=0.956 \mathrm{~nm}, b$ (chain axis) $=1.724 \mathrm{~nm}, c=0.801 \mathrm{~nm}$, $\left.\beta=67.5^{\circ}\right),{ }^{18}$ and should be assigned to the 001,200 and/or 201 reflections from the N6 $\gamma$-form. ${ }^{16,17}$

(2) N66 films $(N 6 / N 66=0 / 100)$. Figure $2 \mathrm{e}$ is a SAED pattern obtained at $0^{\circ}$ in which only one reflection-ring is observed. This reflection-ring is sharp and has fairly uniform intensity distribution along its Debye-Scherrer circle. The appearance of this reflection-ring is similar to that in Figure 2a, but the lattice spacing of this reflection was measured to be $0.438 \mathrm{~nm}$. In Figure 2e, a weak, diffuse ring-like halo located just outside the sharp reflection-ring is recognized. When the specimen was tilted around the vertical axis by $50^{\circ}$, the equatorial part of this reflectionring disappeared and the meridional part still remained (see Figure $2 \mathrm{e}^{\prime}$ ). The four off-meridional parts on the same Debye-Scherrer circle are well recognized in Figure $2 \mathrm{e}^{\prime}$, showing a four-point-like reflection: its lattice spacing was estimated at $0.433 \mathrm{~nm}$. Weak broad reflection-arcs have appeared off-meridionally at the higher angle end of the halo observed in Figure 2e: the spacing of the arcs was measured to be $0.391 \mathrm{~nm}$. The broad arcs are observable on the equator, but are not 

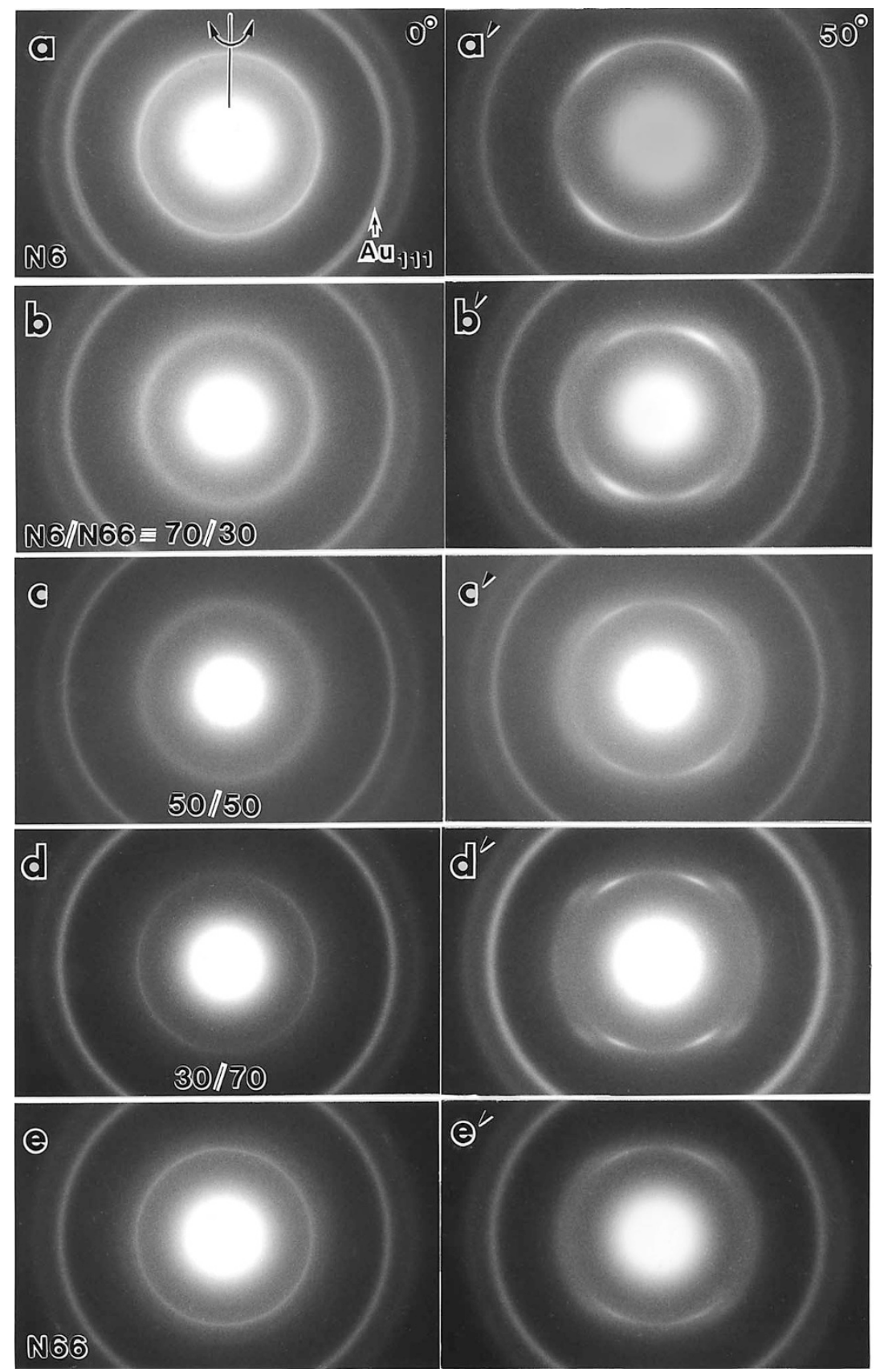

Figure 2. SAED patterns $\left(0^{\circ}\right.$ (untilted) and tilted by $\left.50^{\circ}\right)$ taken from an $8-\mu \mathrm{m}$ diameter specimen-area of each thin film which was as-cast from a $0.2 \mathrm{wt} \%$ solution in formic acid onto the surface of water thermostated at $65^{\circ} \mathrm{C}$. Because all the specimens here were coated with vapor-deposited $\mathrm{Au}$, the outermost two rings in each pattern are reflections from $\mathrm{Au}$, as marked in (a). Each specimen film was tilted around the vertical axis of the figure, as indicated in (a). (a) N6, namely N6/N66 = 100/0; untilted $\left(0^{\circ}\right)$, ( $\left.\mathrm{a}^{\prime}\right)$ tilted by $50^{\circ}$. (b) N6/N66 = 70/30; untilted $\left(0^{\circ}\right),\left(b^{\prime}\right)$ tilted by $50^{\circ}$. (c) N6/N66 $=50 / 50$; untilted $\left(0^{\circ}\right)$, ( (c') tilted by $50^{\circ}$. (d) N6/N66 = 30/70; untilted $\left(0^{\circ}\right)$, (d') tilted by $50^{\circ}$. (e) N66, namely N6/N66 $=0 / 100$; untilted $\left(0^{\circ}\right),\left(\mathrm{e}^{\prime}\right)$ tilted by $50^{\circ}$.

recognized on the meridian.

Judging from the measured lattice spacings of the sharp reflections $\left(0.438 \mathrm{~nm}\right.$ at $0^{\circ}$ (untilted) and $0.433 \mathrm{~nm}$ at $50^{\circ}$ ) and that of the weak broad arcs $\left(0.391 \mathrm{~nm}\right.$ at $\left.50^{\circ}\right)$, it was confirmed that the sharp reflections and the broad arcs are respectively the 100 reflection and the combined $010+110$ one of N66 $\alpha$-form (triclinic $(P \overline{1}) ; a=0.49 \mathrm{~nm}, b=0.54 \mathrm{~nm}, c$ (chain axis) $\left.=1.72 \mathrm{~nm}, \alpha=48.5^{\circ}, \beta=77^{\circ}, \gamma=63.5^{\circ}\right),{ }^{19}$ as already reported in the case of N66 thin films as-cast from solution ${ }^{14,15}$ and melt-crystallized ${ }^{11}$ and also in the case of unoriented N66 prepared for X-Ray diffraction. ${ }^{19}$ Our experimental result, as demonstrated in Figrues $2 \mathrm{e}$ and $2 \mathrm{e}^{\prime}$, is basically similar to the results reported before, ${ }^{14,15}$ in which in the case of as-cast N66 films, the outer combined $010+110$ reflection weaker than the 100 one was clearly recognized only when the specimen film was tilted, for example, by $45^{\circ}$ in a TEM column. On the other hand, melt-crystallized thin films of N66 gave undoubtedly the $010+110$ reflection-ring 
without specimen tilting although this ring was weaker and somewhat broader than the innermost 100 one. ${ }^{11}$ No $00 l$ reflections were recognized, even in this study (see Figures $2 \mathrm{e}$ and $2 \mathrm{e}^{\prime}$ ).

(3) Blend films of N6/N66 $=50 / 50$. Figures $2 \mathrm{c}$ and $2 \mathrm{c}^{\prime}$ are SAED patterns obtained from the same specimen at $0^{\circ}$ (untilted) and at $50^{\circ}$, respectively. In Figure $2 \mathrm{c}$, one broad reflection-ring (measured lattice spacing $=c a .0 .44 \mathrm{~nm}$ ) is observed. When the specimen was tilted by $50^{\circ}$, a SAED pattern (Figure $2 \mathrm{c}^{\prime}$ ) similar to Figure $2 \mathrm{e}^{\prime}$ was obtained. The spacings of the inner arcs and of the outer broad ones were, respectively, estimated at $0.434 \mathrm{~nm}$ and about $0.38 \mathrm{~nm}$. These are here assigned provisionally to the 100 reflection and to the $010+110$ one of N66 $\alpha$-form, respectively, by extending the result obtained for N66 (N6/N66 = 0/100) films (this extension is also applied to the other blends (namely, N6/N66 = 70/30 and 30/70)). The broad reflection-ring ( $c a .0 .44 \mathrm{~nm}$ ) in Figure 2c is also provisionally assigned to 100 of N66 $\alpha$-form. (As mentioned below in Concluding Remarks, these reflections might come from the N6 $\alpha$-form ${ }^{18}$ and/or the N66 $\beta$-form. ${ }^{19}$ Such possibility should, of course, be considered also for the blends of N6/N66 $=70 / 30$ and 30/70.) It is, however, noted that no reflections assigned to the N6 $\gamma$-form were recognized although several SAED patterns were recorded from the films of N6/N66 $=50 / 50$ in which the content of $\mathrm{N} 6$ was $50 \mathrm{wt} \%$.

(4) Blend films of N6/N66 $=70 / 30$. SAED patterns (Figrues $2 b$ and $2 b^{\prime}$ ) obtained from these films are very similar to those (Figrues $2 \mathrm{c}$ and $2 \mathrm{c}^{\prime}$ ) obtained from N6/N66 $=50 / 50$, respectively. The SAED pattern in Figure $2 b^{\prime}$ is similar to that in Figure $2 e^{\prime}$, but the inner reflection-arc in Figure $2 b^{\prime}$ is broader than that in Figure $2 \mathrm{e}^{\prime}$. This result seems to indicate the smaller crystallite size and/or the considerable lattice distortion of crystallite in the blends of N6/N66 $=70 / 30$. The lattice spacing of the broad reflection-ring in Figure $2 \mathrm{~b}$ obtained at $0^{\circ}$ (untilted) is about $0.44 \mathrm{~nm}$. In Figure $2 \mathrm{~b}^{\prime}$ obtained at $50^{\circ}$, the spacings of the inner intense arc and of the weak broad one are respectively $0.438 \mathrm{~nm}$ and about $0.37 \mathrm{~nm}$. Accordingly, the intense arc-shaped reflection and the weak broad one are provisionally assigned, respectively, to 100 and $010+110$ reflections of N66 $\alpha$-form. The broad reflection-ring ( $c a .0 .44 \mathrm{~nm})$ in Figure $2 b$ is also provisionally assigned to 100 of N66 $\alpha$-form, as in the case of the blend films of N6/N66 = $50 / 50$. No reflections assigned to the N6 $\gamma$-form were recognized for the blend films of this composition in spite of the large content of N6 component (70\%).

(5) Blend films of N6/N66 $=30 / 70$. SAED patterns (Figures $2 \mathrm{~d}$ and $2 \mathrm{~d}^{\prime}$ ) obtained from these films are apparently similar to those (Figures $2 \mathrm{e}$ and $2 \mathrm{e}^{\prime}$ ) ob- tained from N66, respectively. In Figure 2d, however, a diffuse halo is not observed. The lattice spacing of the partly oriented but almost ring-like sharp reflection in Figure $2 \mathrm{~d}$ obtained at $0^{\circ}$ (untilted) is estimated at $0.437 \mathrm{~nm}$. In Figure $2 \mathrm{~d}^{\prime}$ obtained at $50^{\circ}$, the measured spacing of the inner sharp arc and that of the weak broad one are respectively $0.433 \mathrm{~nm}$ and $0.379 \mathrm{~nm}$. Accordingly, the sharp reflections $\left(0.437 \mathrm{~nm}\right.$ at $0^{\circ}$ and $0.433 \mathrm{~nm}$ at $\left.50^{\circ}\right)$ and the weak broad one $(0.379 \mathrm{~nm})$ are assigned, respectively, to the 100 reflection, taking account of the composition (N6/N66 =30/70), and provisionally to the $010+110$ one of N66 $\alpha$-form. For this composition, any reflections assigned to the $\gamma$-form of N6 were not recognized.

\section{CONCLUDING REMARKS}

Thin films of nylon-6 (N6), nylon-6,6 (N66) and their blends (N6/N66 $=70 / 30,50 / 50$, and 30/70) were prepared by casting each solution $(0.2 \mathrm{wt} \%)$ in formic acid onto the surface of water thermostated at 55,65 , or $75^{\circ} \mathrm{C}$. Among the three temperatures, $65^{\circ} \mathrm{C}$ was found to be the optimal temperature for all the blend compositions when the solution concentration was fixed to be $0.2 \mathrm{wt} \%$. All specimen films (N6/N66 $=100 / 0,70 / 30$, $50 / 50,30 / 70$, and $0 / 100$ ) were undoubtedly crystalline, judging from SAED, and had the fibrillar entities. All the films evidently showed spherulitic textures. A tilting series $\left(0^{\circ}\right.$ and $\left.50^{\circ}\right)$ of SAED patterns obtained from a film of N6 $(\mathrm{N} 6 / \mathrm{N} 66=100 / 0)$ revealed that such a film of N6 as-cast from its solution in formic acid consists of $\gamma$-form crystallites. SAED patterns obtained from an as-cast film of N66 (N6/N66 = 0/100) were well identified to be the $\alpha$-form of N66. In the SAED patterns obtained from as-cast blend films, however, no reflections assigned to the $\gamma$-form of N6 were recognized. N66 component has a certain depression effect on the formation of $\gamma$-form crystallites of N6 in thin blend films as-cast from solution in formic acid.

For all the blend films of N6 and N66, the two reflections corresponding to the lattice spacings of $0.37-$ $0.38 \mathrm{~nm}$ and $0.433-0.44 \mathrm{~nm}$ were observed, and were provisionally assigned, respectively, to the $010+110$ reflection and the 100 one of N66 $\alpha$-form by extending the result obtained for N66 (namely, N6/N66 = 0/100), in Part (3) through Part (5) of Results and Discussion. It should be remembered, however, that the N6 $\alpha$-form ${ }^{18}$ also gives two reflections with comparable lattice spacings of $0.36-0.37 \mathrm{~nm}(002+202$ reflection $)$ and of $0.44 \mathrm{~nm}$ (200 one). ${ }^{11}$ Therefore, the two reflections in question, which were observed for the blend films, most likely indicate that both N6 and N66 crystallized in their respective $\alpha$-forms in the blend films, 
Table I. Crystal forms of N6 and N66 in their blend films as-cast from solution in formic acid onto water surface thermostated at $65^{\circ} \mathrm{C}$

\begin{tabular}{cccccc}
\hline Composition (N6/N66) & $100 / 0$ & $70 / 30$ & $50 / 50$ & $30 / 70$ & $0 / 100$ \\
\hline \multirow{2}{*}{ Crystal form ${ }^{\mathrm{a}} \mathrm{N} 6$} & $\gamma$ & $(\alpha)$ & $(\alpha)$ & {$[\alpha]$} & - \\
& - & {$[\alpha]$} & $(\alpha)$ & $(\alpha)$ & $\alpha$ \\
\hline
\end{tabular}

${ }^{a}$ A probable crystal form is designated in parentheses, but has not yet been identified crystallographically. An assumed crystal form is indicated in the square brackets. To make this table, the compositions were taken into consideration.

as summarized in Table I by taking the compositions into account. At the present stage, however, the possibility of N66 $\beta$-form (triclinic $(P \overline{1}) ; a=0.49 \mathrm{~nm}$, $b=0.80 \mathrm{~nm}, c$ (chain axis) $=1.72 \mathrm{~nm}, \alpha=90^{\circ}$, $\left.\beta=77^{\circ}, \gamma=67^{\circ}\right)^{19}$ might not be disregarded for the blend films when they are made by casting from solution in formic acid. ${ }^{21}$ Although the $\beta$ mesomorphic form of N6 has recently been reported for melt-spun fibers, ${ }^{20}$ this $\beta$-form of N6 was disregarded in this study by judging from our method of specimen preparation (namely, a solution-casting method). More study is, of course, needed for further detailed structural analysis of the blend films.

Acknowledgments. The authors would like to thank Research and Development Center, Unitika Ltd., for providing the materials (N6 and N66). E. L. Bedia thanks the JSPS-DOST RONPAKU (Dissertation Ph.D.) Program (ID No. DOST-9723) for the financial support.

\section{REFERENCES}

1. M. I. Kohan, Ed. "Nylon Plastics Handbook", HanserGardner Publications, Munich, 1995.

2. T. Kitao, H. Kobayashi, S. Ikegami, and S. Ohya, J. Polym. Sci., Polym. Chem. Ed., 11, 2633 (1973).

3. A. Verma, B. L. Deopura, and A. K. Sengupta, J. Appl. Polym. Sci., 31, 747 (1986).

4. K. N. Bhaumik, B. L. Deopura, and V. K. Srivastava, Int. J.
Polym. Mater., 18, 71 (1992).

5. F. Rybnikár and P. H. Geil, J. Appl. Polym. Sci., 46, 797 (1992).

6. F. Rybnikár and P. H. Geil, J. Appl. Polym. Sci., 49, 1175 (1993).

7. T. Matsuda, T. Shimomura, and M. Hirami, Polym. J., 31, 795 (1999).

8. M. Hirami and T. Matsuda, Polym. J., 31, 801 (1999).

9. K. Matsumura, T. Shimomura, T. Matsuda, and M. Hirami, Polym. J., 31, 836 (1999).

10. T. Shimomura, T. Matsuda, and M. Hirami, Polym. J., 31, 840 (1999).

11. E. L. Bedia, M. Tsuji, M. Tosaka, M. Ohara, and S. Kohjiya, J. Macromol. Sci., Phys., B40, 1079 (2001).

12. M. Kurokawa, Dissertation for the doctorate in fiber chemistry (Engineering), Kyoto University, 1961.

13. R. Eppe, E. W. Fischer, and H. A. Stuart, J. Polym. Sci., 34, 721 (1959).

14. R. G. Scott, J. Appl. Phys., 28, 1089 (1957).

15. A. Keller, J. Polym. Sci., 36, 361 (1959).

16. T. Ohta, O. Yoshizaki, and E. Nagai, Kobunshi Kagaku, 20, 225 (1963).

17. H. Arimoto, M. Ishibashi, and M. Hirai, J. Polym. Sci., A, 3, 317 (1965).

18. D. R. Holmes, C. W. Bunn, and D. J. Smith, J. Polym. Sci., 17, 159 (1955).

19. C. W. Bunn and E. V. Garner, Proc. R. Soc. London. Ser. A., 189, 39 (1947).

20. F. Auriemma, V. Petraccone, L. Parravicini, and P. Corradini, Macromolecules, 30, 7554 (1997).

21. K. Monobe and A. Kawaguchi, Chemistry (Kagaku), 21, 891 (1966). 